\title{
REVIEW \\ Molecular genetics and cellular events of K-Ras-driven tumorigenesis
}

\author{
GG Jinesh ${ }^{1,5}$, V Sambandam ${ }^{2,5}$, S Vijayaraghavan ${ }^{3,5}, \mathrm{~K}$ Balaji $^{3,5}$ and S Mukherjee ${ }^{4,5}$
}

Cellular transformation and the accumulation of genomic instability are the two key events required for tumorigenesis. K-Ras (Kirsten-rat sarcoma viral oncogene homolog) is a prominent oncogene that has been proven to drive tumorigenesis. K-Ras also modulates numerous genetic regulatory mechanisms and forms a large tumorigenesis network. In this review, we track the genetic aspects of K-Ras signaling networks and assemble the sequence of cellular events that constitute the tumorigenesis process, such as regulation of K-Ras expression (which is influenced by miRNA, small nucleolar RNA and IncRNA), activation of K-Ras (mutations), generation of reactive oxygen species (ROS), induction of DNA damage and apoptosis, induction of DNA damage repair pathways and ROS detoxification systems, cellular transformation after apoptosis by the blebbishield emergency program and the accumulation of genomic/chromosomal instability that leads to tumorigenesis.

Oncogene (2018) 37, 839-846; doi:10.1038/onc.2017.377; published online 23 October 2017

\section{INTRODUCTION}

Cancer remains a difficult disease to cure and the most common cause of disease-associated mortality. An incomplete understanding of the tumorigenesis process and the generation of heterogeneity within tumors renders therapeutic measures ineffective against cancer. Accumulating evidences point to the fact that the clones that develop resistance to therapy are cancer stem cells ${ }^{1}$ and often have genetic alterations in K-Ras. ${ }^{2}$ One major reason for heterogeneity/clonal difference is genomic instability, which generates cancer cells with structural or numeric chromosomal alterations that result in alterations to critical genes such as $\mathrm{K}-$ Ras $^{3}$ that govern cell survival and immune evasion. In this review, we track the genetic aspects and sequence of cellular events that constitute the K-Ras-driven tumorigenesis process as a model for oncogene-driven tumorigenesis, with special focus on the role of cellular transformation and genomic instability and how RNA interference of K-Ras influences tumorigenesis.

\section{K-RAS: GENETIC REGULATION OF EXPRESSION AND ACTIVATION}

Ras oncogenes (HRAS, KRAS and NRAS) were discovered from viruses and were found to have transforming (sphere/focusforming/anchorage-independent growth/clonogenic growth) properties. ${ }^{4}$ KRAS encodes a $21 \mathrm{kDa}$ protein product and is a powerful member of the Ras oncogene family. KRAS has two alternatively spliced mRNA variants, namely, KRAS4A and KRAS4B. ${ }^{4}$ Human cells harbor the KRAS gene at chromosomal band $12 \mathrm{p} 12.1^{5}$

Once the KRAS gene is transcribed, the mRNA is either subjected to translation or RNA interference-mediated degradation (Figure 1 and Table 1). Let-7 micro-RNA (miR/miRNA) targets
K-Ras mRNA for degradation through LCS (Let-7 complementary sites) within the K-Ras mRNA. ${ }^{6,7}$ Interestingly, Chin et al. ${ }^{8}$ used clinical specimens to identify that an LCS6 variant allele with a mutation in the miRNA-binding region was associated with K-Ras overexpression. H19 long non-coding RNA (IncRNA) blocks K-Ras mRNA degradation by antagonizing Let-7 miRNAs. ${ }^{9}$ Moreover, miR-16 directly targets the $3^{\prime}$-UTR of KRAS mRNA to block K-Ras expression $^{10}$ (Figure 1). The extent to which miRNAs cross react with mRNAs of other ras oncogenes is not well understood. However, miRNA-18a was found to specifically target K-Ras mRNA without targeting transcripts of $\mathrm{N}$-Ras or $\mathrm{H}$-Ras ${ }^{11}$ (Figure 1). Furthermore, miRNA-622, ${ }^{12}$ miR-1/hsa-miR-1, ${ }^{13}$ miR-217, ${ }^{14}$ miR$-143 / 145$ (discussed below) and small nucleolar RNAs (discussed below) are also capable of targeting K-Ras expression (Figure 1).

Simply expressing K-Ras is not sufficient for tumorigenesis because when K-Ras was expressed under its own endogenous promoter with a conditional interferon inducible switch, it could only induce transformation and not acute myeloid leukemia. ${ }^{15}$ Thus, the genetic aspects of KRAS promoter regulation is not discussed in detail here. Genomic instability in combination with cellular transformation was suggested to enable K-Ras-driven tumorigenesis. ${ }^{15}$ This combination of cellular transformation and genomic instability also holds true for human papillomavirusinduced tumorigenesis. ${ }^{16}$

The expression of KRAS alone did not drive tumorigenesis because it did not account for the activation of K-Ras. When K-Ras is bound to guanosine diphosphate, it is in its inactive form, and when this guanosine diphosphate is replaced with guanosine triphosphate, K-Ras becomes activated. ${ }^{4}$ Activated cell surface receptors (usually receptor tyrosine kinases/RTKs) activate K-Ras. RTKs and Ras signaling collaborate to develop specific sub-types of cancer and thus are important for cancer therapy. ${ }^{17}$ Apart from

\footnotetext{
${ }^{1}$ Department of Urology, University of Texas MD Anderson Cancer Center, Houston, TX, USA; ${ }^{2}$ Thoracic Head \& Neck Medical Oncology Department, University of Texas MD Anderson Cancer Center, Houston, TX, USA; ${ }^{3}$ Department of Experimental Radiation Oncology, University of Texas MD Anderson Cancer Center, Houston, TX, USA and

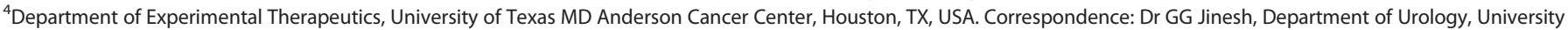
of Texas MD Anderson Cancer Center, 1515 Holcombe Boulevard, Houston, TX 77030, USA.

E-mail: goodwinjinesh@gmail.com

${ }^{5}$ All authors contributed equally to this work.

Received 20 April 2017; revised 11 August 2017; accepted 8 September 2017; published online 23 October 2017
} 
protein-based activation, K-Ras also becomes constitutively activated by mutations in critical codons. High-frequency mutations (in clinical specimens), such as G12A, G12C, G12D, G12S, G12V, G13C and G13D, in addition to many other low-frequency mutations, are known to activate K-Ras ${ }^{18-23}$ (Figure 1 and Table 1). These mutations interfere with guanosine triphosphate hydrolysis to make K-Ras constitutively active. ${ }^{24,25}$ However, this concept was recently questioned because the binding of guanosine triphosphate to mutant K-Ras may vary depending on the type of mutation. ${ }^{26}$ The K-Ras ${ }^{\text {G13D }}$ mutation directs ZNF304-DNMT1mediated repression of tumor suppressor genes through promoter methylation. ${ }^{27}$ K-Ras mutations are frequently observed in cancers of the pancreas (57\%), large intestine (33\%), biliary tract (31\%), small intestine (20\%), lung (17\%), endometrium (14\%), ovary $(14 \%)$, prostate $(8 \%)$, cervix $(7 \%)$, stomach $(6 \%)$, urinary tract $(5 \%)$, liver (5\%), haematopoietic cells $(5 \%)$ and other organs $(<5 \%) .{ }^{4}$ However, this could be an underestimation of the actual $\mathrm{K}$-Ras activation status in cancer because these percentages only account for the mutant KRAS and not receptor-activated wild-type

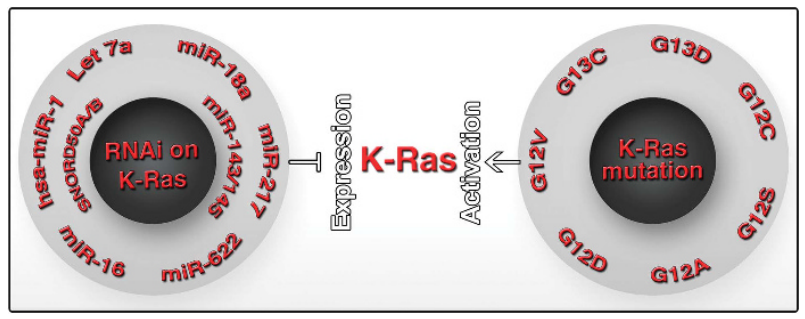

Figure 1. Key genetic factors regulating KRAS expression and K-Ras activation. Key miRNAs/snoRNAs targeting KRAS mRNA and inhibiting K-Ras expression are shown on the left, and the most frequent and prominent K-Ras mutations leading to constitutive K-Ras activation are shown on the right (see text for references).
K-Ras. Mutations enable the oncogenic characteristics of both splice variants of KRAS (KRAS4A and KRAS4B). ${ }^{28}$ Wild-type K-Ras activation modules are protein-based modifications and will not be discussed in detail here. For more details on this and on small molecule inhibition of K-Ras, please see the latest excellent review. $^{29}$

Epidermal growth factor receptor (EGFR), one of the prominent candidates implicated in cellular transformation, is tightly linked to K-Ras-induced pancreatic tumorigenesis. ${ }^{30}$ In addition, VEGFR2/ KDR expression and PDGFRA expression were found to correlate

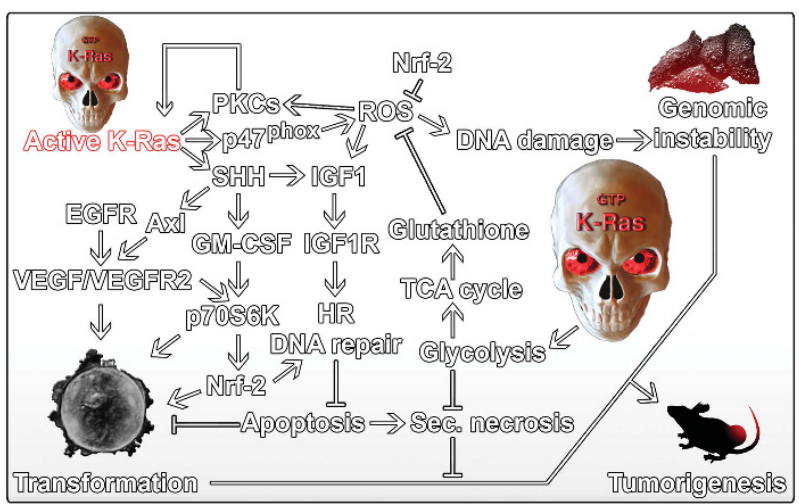

Figure 2. Cellular transformation and genomic instability are required for K-Ras-driven tumorigenesis. Key signaling pathways from activated K-Ras that lead to cellular transformation and genomic instability in various cancers. EGFR, epidermal growth factor receptor; GM-CSF, granulocyte monocyte-colony stimulating factor; HR, homologous recombination; IGF, insulin-like growth factor; PKC, protein kinase-C; ROS, reactive oxygen species; $\mathrm{SHH}$, sonic hedgehog; TCA cycle, tri-carboxylic acid cycle; VEGF, vascular endothelial growth factor.

Table 1. Genetic and cellular events that regulate K-Ras-driven tumorigenesis

\begin{tabular}{|c|c|c|}
\hline Major event & Negative regulation & Positive regulation \\
\hline $\begin{array}{l}\text { K-Ras-regulated } \\
\text { non-coding } \\
\text { RNAs }\end{array}$ & Potential miRNA target (miR-1298). & miRNAs (miR-21, and miR-214), and IncR-ANRIL. \\
\hline $\begin{array}{l}\text { Apoptosis } \\
\text { induction }\end{array}$ & $\begin{array}{l}\text { Antioxidant system (Nrf-2, SLC7A5, HMOX-1, NQO1), IRES translation } \\
\text { of c-IAPs (c-IAP1/2, XIAP) and induction of DNA repair pathways. }\end{array}$ & ROS-induced DNA damage \\
\hline $\begin{array}{l}\text { Secondary } \\
\text { necrosis }\end{array}$ & $\begin{array}{l}\text { BAD-Ser-112 phosphorylation by } \mathrm{p} 70 \mathrm{~S} 6 \mathrm{~K} \text { and Pim-1 to boost } \\
\text { glycolysis to generate ATP. }\end{array}$ & Lack of ATP after glycolytic shut down. \\
\hline $\begin{array}{l}\text { Blebbishield } \\
\text { formation }\end{array}$ & $\begin{array}{l}\text { Dynasore (Dynamin-dependent endocytosis inhibitor), and } \mathrm{N} \text { - } \\
\text { ethylmaleimide (NEM). }\end{array}$ & $\begin{array}{l}\text { Dynamin-dependent endocytosis, serpentine filopodia } \\
\text { formation and membrane fusion. }\end{array}$ \\
\hline $\begin{array}{l}\text { Blebbishield- } \\
\text { mediated } \\
\text { transformation }\end{array}$ & Neutralizing antibodies to VEGF-A and VEGFR2. & $\begin{array}{l}\text { VEGF-A, VEGFR2, cell fusion, lactic acid, IRES translation } \\
\text { and p70S6K. }\end{array}$ \\
\hline Tumorigenesis & $\begin{array}{l}\text { miRNAs (miR-216, miR-1298, miR-143/145, miR-16, Let-7a, miR-214, } \\
\text { hsa-miR-1, miRNA-622, miR-217, miR-30a), induction of proper } \\
\text { immunogenic apoptosis (wild-type p53, p21, cleaved Bax/Bak) and } \\
\text { senescence (pRb) and snoRNAs (SNORD50A, SNORD50B). }\end{array}$ & $\begin{array}{l}\text { K-Ras expression and activation, miRNAs (miR-21, } \\
\text { miR-26a), IncRNA ANRIL, FAK, ERK-1/2, glycolytic switch, } \\
\text { cellular transformation, genomic instability, evasion of } \\
\text { apoptosis and immunity, and overriding cell cycle } \\
\text { checkpoints. }\end{array}$ \\
\hline Cancer therapy & $\begin{array}{l}\text { Blebbishield emergency program (inhibits cell death), glycolysis } \\
\text { (inhibits secondary necrosis after apoptosis) and lack of functional } \\
\text { wild-type p53. }\end{array}$ & $\begin{array}{l}\text { K-Ras inhibitors, miRNA therapeutics, glycolysis } \\
\text { inhibitors with apoptosis inducers, immunotherapeutics } \\
\text { and other preclinical therapeutics. }\end{array}$ \\
\hline
\end{tabular}


with K-Ras codon 12 and 13 mutations in colorectal cancer. ${ }^{31}$ K-Ras ${ }^{\mathrm{G} 12 \mathrm{D}}$ mutant cells regulate granulocyte monocyte-colony stimulating factor and granulocyte-colony stimulating factor secretion through sonic hedgehog-dependent recruitment of tumor stroma. ${ }^{32}$ All these factors govern cellular transformation and genomic instability to cause tumorigenesis (Figure 2). Sonic hedgehog induces IGF1 and GAS6 to activate IGF1R and AXL/ TYRO3, respectively, leading to downstream AKT (pT308/pS473), MEK and IRS- 1 activation. ${ }^{32}$ Often, K-Ras mutations mimic the activation of RTKs and thus cause resistance to most RTK inhibitors because RTKs are upstream of K-Ras activation. For example, K-Ras mutation contributes resistance to IGF1R tyrosine kinase inhibitors. ${ }^{33}$ On the other hand, the inhibition of AXL suppresses DNA damage responses and sensitizes cancer cells to PARP inhibitors. ${ }^{34}$ Thus, K-Ras either directly or indirectly drives the resistance of cancer cells to therapeutic agents that target RTKs (Figure 2).

\section{K-RAS: INDUCTION OF ROS, APOPTOSIS AND ROS DETOXIFICATION IN CELLULAR TRANSFORMATION}

Once activated, K-Ras has a plethora of functions; however, the induction of reactive oxygen species (ROS) is the key step toward cellular transformation, genomic instability and tumorigenesis. K-Ras orchestrates ROS production by promoting the localization of NOX1 component $\mathrm{p} 47^{\text {phox }}$ to the plasma membrane and facilitates its interaction with protein kinase-C isoforms (PKC) to mediate cellular transformation ${ }^{35}$ (Figures 2 and 3 and Table 1). In addition, K-Ras activation is linked to an altruistic positive feedback loop between PKC- $\zeta$, p47phox, and ROS wherein K-Ras facilitates $p 47^{\text {phox }}$ to generate ROS, and ROS offers sustained activation status for PKC- $\zeta$ because PKC- $\zeta$ and $p 47^{\text {phox }}$ are interacting partners ${ }^{36}$ (Figures 2 and 3). PKCs in turn phosphorylate both K-Ras isoforms (KRAS4A and KRAS4B) at Ser-181 to activate K-Ras. ${ }^{37,38}$ ROS production is, however, deleterious to cells as it can damage DNA through oxidative stress and induce apoptosis. Paradoxically, K-Ras can induce apoptosis, as well as promote tumorigenesis. ${ }^{39}$ Although these functions are contradictory in nature, ROS-induced apoptosis ${ }^{36,40}$ and K-Ras/VEGF/ p19-VHL-directed survival functions (ROS neutralization by IGFBP3, $S L C 7 A 5$ and $S L C 3 A 2^{41}$ ) are utilized in sequence to complete cellular transformation by the blebbishield emergency program. ${ }^{42-44} \mathrm{Pim}$ kinase isoforms are instrumental in protecting mitochondria from damage because loss of Pim kinase isoforms correlates with damage to mitochondria and the inhibition of cellular

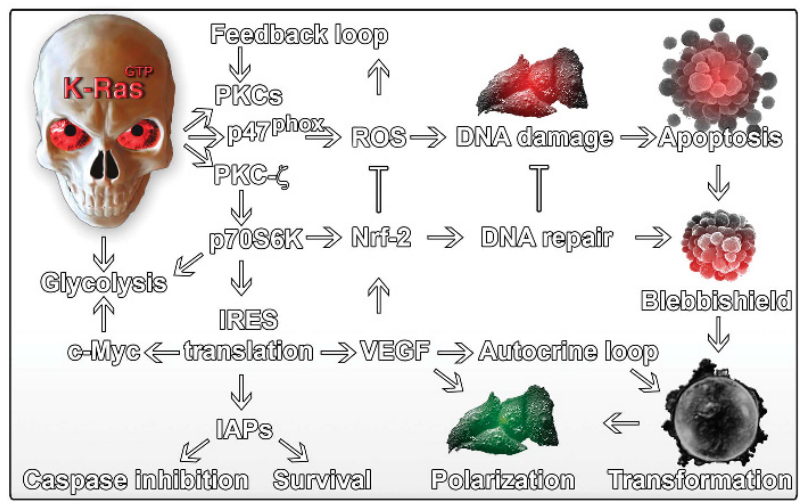

Figure 3. Cellular transformation after apoptosis by the blebbishield emergency program. Key signaling pathways from activated K-Ras that lead to cellular transformation by promoting glycolysis, inhibiting apoptosis through IAPs and ROS detoxification. IAPs, inhibitor of apoptotic proteins (XIAP, CIAP-1/2); IRES, internal ribosome entry site; $\mathrm{PKC}$, protein kinase-C; ROS, reactive oxygen species; VEGF, vascular endothelial growth factor. transformation. ${ }^{40}$ Inhibition of ROS by targeting PKC- $\zeta$ and $\mathrm{p} 47^{\text {phox }}$ abrogates cellular transformation. ${ }^{36}$ Thus, persistent altruistic feedback from ROS is needed to keep PKC- $\zeta$ active to regulate the expression of survival signals such as vascular endothelial growth factor (VEGF) and c-IAP2 through internal ribosome entry site (IRES) translation (Figure 3).

Persistent ROS generation can damage DNA and can activate p53 to promote full-blown apoptosis. ${ }^{45,46}$ To prevent p53 activation, K-Ras must either control the level of ROS generation or neutralize ROS. ROS detoxification is one way by which K-Ras and K-Ras ${ }^{\mathrm{G} 12 \mathrm{D}}$ overcome the deleterious effects of ROS. K-Ras regulates the expression of a panel of ROS detoxification mediators such as Nrf- $2,{ }^{47} \mathrm{NQO} 1,{ }^{48}$ and HMOX-1 to promote K-Ras-driven tumorigenesis ${ }^{49}$ (Table 1). Expression of the chief ROS detoxification mediator Nrf-2 in response to ROS is under the control of protein translation through p70S6K, ${ }^{50}$ which in turn is a downstream target of PKC- $\zeta^{51}$ (Figure 3). Thus, constitutive K-Ras activation leads to the constitutive activation of an altruistic feedback loop of ROS generation and sustained PKC activation, in which PKC- $\zeta$ drives the activation of $\mathrm{p} 70 \mathrm{~S} 6 \mathrm{~K}$ and regulates the expression of Nrf-2 to neutralize the toxic effects of ROS (Figure 3).

\section{K-RAS AND BLEBBISHIELD-MEDIATED CELLULAR TRANSFORMATION AFTER APOPTOSIS}

Soft-agar transformation assay has been the method of choice for decades to test the transforming ability of individual oncogenes. K-Ras knock-in was found to transform non-tumorigenic cells. ${ }^{52}$ Interestingly, soft-agar transformation is a long assay and takes days to weeks to reach an endpoint. Hence, the short-term events during cellular transformation were obscured for a long time. In the quest to understand cancer stem cells between low and high tumorigenic versions of bladder cancer cells, it was found that sphere formation (transformation) was preceded by apoptosis and a subsequent blebbishield emergency program, which rescues apoptotic cells and redirects them toward K-Ras-mediated cellular transformation ${ }^{36,42,43,53}$ (Figure 3).

Smac mimetics in combination with death ligands such as tumor necrosis factor-a or tumor necrosis factor-related apoptosis inducing ligand were found to effectively abrogate K-Ras activation, leading to massive cell death in cancer cells. ${ }^{44}$ Although FasL in combination with a Smac mimetic could induce apoptosis in cancer cells, a subset of apoptotic cells managed to survive after apoptosis and underwent cellular transformation (sphere formation) using the blebbishield emergency program. ${ }^{44}$ The blebbishield emergency program constructs blebbishields from apoptotic bodies using dynamin-dependent endocytosisdriven serpentine filopodia, and the blebbishields in turn fuse to each other to undergo cellular transformation. ${ }^{36,42,43,53-55}$ The transformation phase of the blebbishield emergency program is driven by VEGF-activated VEGFR2 to activate K-Ras ${ }^{4,44}$ (Table 1). K-Ras signaling activates p70S6K (through ROS, PKC- $\zeta$ axis) to enhance IRES translation of VEGF to activate the VEGF autocrine loop $^{44}$ (Figure 3 ). The blebbishields sustain VEGF secretion by maintaining p70S6K activation and thus continue IRES translation even during apoptosis. ${ }^{44,56}$ IRES translation also provides survival signals in the form of inhibitor of apoptotic proteins (IAPs) ${ }^{44}$ (Figure 3 and Table 1). DNA damage response is very important in the context of the blebbishield emergency program because DNA damage is a hallmark of apoptosis. The Nrf-2-ROS detoxification system has a direct role in activating DNA repair through homologous recombination ${ }^{57}$ (Figure 3 ).

$\mathrm{K}$-Ras was found to be in an oligomerized state in parallel to BAD, Bax, Bak and p27 to boost glycolysis, so that the apoptotic cells were not subjected to secondary necrosis during the blebbishield emergency program. ${ }^{44}$ This could be one of the main reasons why cancer cells prefer glycolysis. Active K-Ras, p70S6K and Pim kinase- 1 isoforms were found to have pivotal 


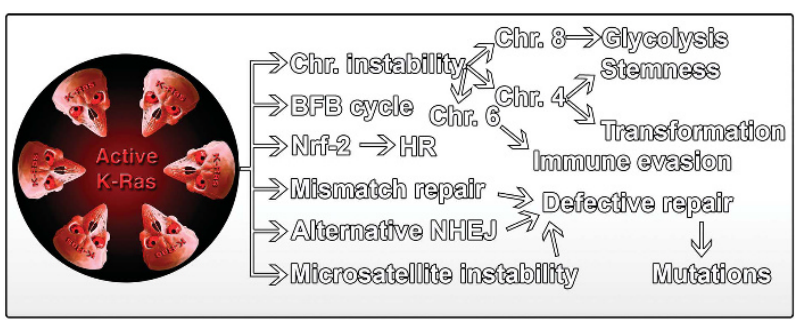

Figure 4. K-Ras-driven genomic instability in tumorigenesis. K-Ras hijacks DNA repair pathways either to make defective repair or to promote survival after apoptotic DNA damage. Chr., chromosome; HR, homologous recombination; NHEJ, non-homologous end joining.

roles in blocking BAD-mediated apoptosis by maintaining the phosphorylation of BAD at its Serine-112 gatekeeper site. ${ }^{40,56}$ Compromising this phosphorylation using Smac mimetics plus tumor necrosis factor-a/tumor necrosis factor-related apoptosis inducing ligand leads to the abrogation of the transformation phase of blebbishield emergency program by promoting the depolarization of mitochondria and the induction of complete apoptosis ${ }^{40,58,59}$ (Table 1). Similarly, interfering with Ser-181 phosphorylation of K-Ras4A and K-Ras4B isoforms blocks tumorigenesis and cellular transformation (foci formation), respectively. ${ }^{37,38}$

The blebbishield emergency program explains why K-Ras and BAD facilitate both apoptosis and cell survival, ${ }^{39,60}$ because apoptosis induction and subsequent survival are necessary for cellular transformation. ${ }^{42,61,62}$ In support of this notion, PARP inhibitors and the caspase-3 inhibitor z-DEVD-fmk were found to abrogate cellular transformation. ${ }^{44,63}$ Furthermore, soft-agar transformation and blebbishield emergency program-mediated cellular transformation are driven by an identical mechanism because a small molecule, CF3-DODA-Me, abrogates cellular transformation in soft-agar assays, as well as blebbishieldmediated sphere formation assay, by targeting drivers of the blebbishield emergency program. ${ }^{64}$

\section{K-RAS: GENOMIC INSTABILITY, THE NEXT CRUCIAL STEP TOWARDS TUMORIGENESIS}

Cellular transformation that is induced by K-Ras is not enough to drive tumorigenesis. For efficient tumorigenesis, cells need to accumulate mutations or genomic instability. ${ }^{15}$ This is, in fact, demonstrated in the case of human papillomavirus-induced tumorigenesis in which transformation and genomic instability together drive tumorigenesis. ${ }^{16}$ Thus, the generation of genomic instability is the next key step in K-Ras-driven tumorigenesis. K-Ras activation causes early tumorigenesis in a mouse model of lung cancer, ${ }^{65}$ suggesting the capability of K-Ras to induce both transformation and genomic instability. Genomic instability can occur within a specific location of the genome (for example, microsatellite instability) or at the chromosomal level as structural and/or numeric alterations (such as ploidy/aneuploidy, breakagefusion-breakage/breakage-fusion-bridge cycle between chromosomes, or the translocation of chromosomal arms, resulting in fusion genes) (Figure 4). Even though cells have DNA repair mechanisms, defective DNA repair can lead to genomic instability.

\section{K-RAS: DNA REPAIR DEFECTS AND GENOMIC INSTABILITY}

Mismatch repair (MMR) is a small-scale DNA repair mechanism in cells. Defective MMR can lead to mutational hotspots/microsatellite instability and could be the cause of K-Ras activating mutations (Figure 4). EGFR is known to phosphorylate PCNA to inhibit MMR; ${ }^{66}$ therefore, it can increase mutation burden. In a pancreatic cancer mouse model, K-Ras upregulated EGFR expression, and genetic interference of EGFR eliminated K-Ras induced tumorigenesis. ${ }^{30}$ Thus, K-Ras is associated with microsatellite instability in cancer, ${ }^{67,68}$ which might require other factors such as PCNA inhibition by EGFR to lead to defective MMR in K-Ras-driven tumorigenesis.

DNA damage that is induced during apoptosis must be repaired by cells to override cell death and to undergo cellular transformation. To ensure protection from DNA damage, K-Rasactivated cells utilize various tactics, including the Nrf-2dependent ROS detoxification system, which not only neutralizes ROS but also activates homologous recombination-mediated DNA repair $^{57}$ (Figure 3). Telomere shortening-induced exposure of naked DNA ends at telomeric regions of chromosomes results in chromosome-chromosome fusion by the non-homologous end joining (NHEJ) mode of DNA repair to form breakage-fusionbridge cycle (BFB cycle) type chromosomes. ${ }^{69,70}$ The classical NHEJ pathway contributes to genomic instability during mitosis if X-ray repair cross-complementing protein 4 (XRCC4) is not phosphorylated at the mitotic phase (M-phase). However, K-Ras targets an alternative XRCC4-independent NHEJ error-prone pathway that includes DNA ligase-3a, Poly (ADP-ribose) polymerase 1 and XRCC1 as components. ${ }^{71}$ Mutant K-Ras is known to upregulate the components of this error-prone alternative NHEJ pathway (DNA ligase-3a, Poly (ADP-ribose) polymerase 1 and XRCC1), and cells depend on this alternative NHEJ pathway during genotoxic stress. $^{71}$ Thus, the MMR, homologous recombination and NHEJ modes of DNA repair can all be misused by K-Ras to generate genomic instability (Figure 4 and Table 1).

\section{K-RAS: CHROMOSOMAL INSTABILITY IN METABOLIC REPROGRAMMING, SURVIVAL AND STEMNESS}

Chromosomal instability is a large-scale genomic alteration with numerical or structural alterations in chromosomes. Deleting p53 in non-tumorigenic epithelial cells resulted in the generation of transformed phenotype and chromosomal instability. ${ }^{72}$ Rodrigues et al. ${ }^{73}$ also found that chromosomal instability is associated with cellular transformation. Thus, a transformation event can also generate chromosomal instability if $\mathrm{p} 53$ is compromised. KRAS mutation coupled to p53 loss can lead to tumorigenesis. ${ }^{74}$ Recently, blebbishield emergency program is found to drive severe chromosomal instability by suppressing the expression of p53 during the transformation phase. ${ }^{61}$ In addition, EGFR, a K-Ras target, induces the expression of miR-26a in non-small cell lung cancer, ${ }^{75}$ and miR-26a promotes chromosomal instability and tumorigenesis in breast cancer cells. ${ }^{76}$

The accumulation of chromosome- 8 has been predominantly correlated with genomic instability in multiple cancer types ${ }^{77}$ (Figure 4). Chromosome-8 harbors the Myc gene, ${ }^{78}$ one of the important targets of K-Ras (through the regulation of IRES translation). ${ }^{44} \mathrm{~K}$-Ras and Myc are regulators of glycolysis to avert secondary necrosis of apoptotic cancer stem cells during blebbishield-mediated transformation ${ }^{44}$ (Figure 3). Thus, the control of K-Ras over metabolic reprogramming ${ }^{79}$ has a potential genetic basis, the chromosome-8 accumulation. Alternatively, mutant K-Ras ${ }^{\text {G12D }}$ copy number influences glucose metabolism and the TCA cycle to generate glutathione for ROS detoxification. ${ }^{80}$ Furthermore, the glycolysis metabolite lactic acid (lactate) offers strong survival advantages to cancer stem cells that undergo cellular transformation using the blebbishield emergency program by reducing the $\mathrm{pH}$ and potentially increasing the bioavailability of VEGF from the microenvironment. ${ }^{42}$ Furthermore, targeting lactate dehydrogenase-A (an enzyme that converts pyruvate to lactate) has been shown to impede cellular transformation $^{81}$ and tumorigenesis. ${ }^{82}$ Thus, the blebbishield emergency program positively selects cells that are capable of 


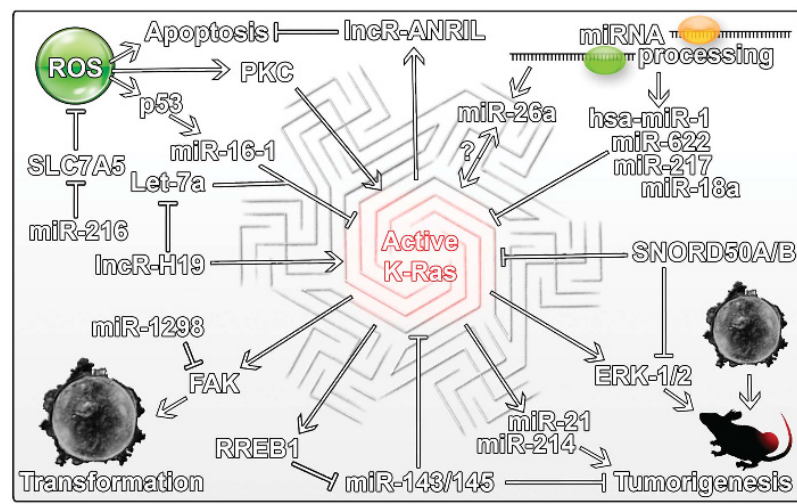

Figure 5. RNA interference that impedes or promotes K-Ras-driven tumorigenesis. Schematic showing RNA interference that inhibits or promotes K-Ras-driven tumorigenesis by targeting cellular transformation, genomic instability or K-Ras. FAK, focal adhesion kinase; IncR, long non-coding RNA; miR, micro-RNA; ROS, reactive oxygen species.

enhanced glycolysis, lactate production and survival after apoptosis.

In addition, K-Ras has been linked to the accumulation of chromosomes-4, 10 and 12 in colorectal carcinomas. ${ }^{83}$ Among these, chromosome- 4 harbors VEGFR2/KDR, c-Kit and PDGFRA in the same cytogenetic band ( $4 q 12)$ as a cluster where VEGFR2/KDR expression and PDGFRA expression were found to correlate with K-Ras codon 12 and 13 mutations in colorectal cancer. ${ }^{31}$ This is very important because VEGF/VEGFR2 signaling drives the blebbishield emergency program for cellular transformation ${ }^{43,44}$ (Figures 2 and 3). Chromosome-4 accumulation could also provide

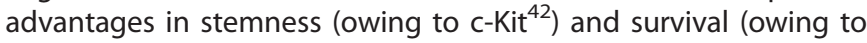
IRES translation of anti-apoptotic factors such as C-IAP2, XIAP, Tau through the VEGFR2/p70S6K axis $^{44}$ ) (Figure 3 and Table 1).

Interestingly, the selective loss of chromosome- 6 was found to be a cause of K-Ras ${ }^{\mathrm{G} 12 \mathrm{D}}$ mutant-mediated immune evasion. ${ }^{2}$ Thus, chromosome loss can also contribute to K-Ras-driven tumorigenesis and immune evasion.

\section{MICRO-RNA, InCRNA, snORNA AND REGULATION OF K-RAS- DRIVEN TUMORIGENESIS}

In general, impaired micro-RNA processing is linked to tumorigenesis. ${ }^{84}$ Interestingly, p53 acts as a switch regulating miRNA processing. ${ }^{85}$ ROS is known to induce the expression and activation of p53 to induce apoptosis, ${ }^{46}$ and hence, miRNA targeting of ROS detoxification mechanisms should help to induce p53 expression or act against K-Ras. In this context, SLC7A5, a ROS detoxification mediator, is a target for miR-216 (Figure 5), and miR-216 targets multiple mediators of K-Ras-driven tumorigenesis to block K-Ras-dependent survival ${ }^{86}$ (Table 1). Similarly, miRNAs that act as indirect targets also impede or enhance K-Ras-driven tumorigenesis. For example, miR-1298 inhibits K-Ras-driven tumor growth by targeting focal adhesion kinase ${ }^{87}$ (Figure 5). In NSCLC, miR-21 enhances K-Ras-driven tumorigenesis by targeting negative regulators of the Ras/MAPK pathway. ${ }^{88}$

In addition, miRNAs that directly target K-Ras signaling also impede or enhance K-Ras-driven tumorigenesis. For example, miR-143/145 blocks K-Ras-mediated tumorigenesis, whereas K-Ras activation suppresses the expression of miR-143/145 through Rasresponsive element-binding protein ${ }^{89}$ (Figure 5). K-Ras expression and tumorigenesis are inhibited by miR-16, which directly targets the $3^{\prime}$-UTR of KRAS mRNA. ${ }^{10}$ Let-7a targets K-Ras to inhibit the malignant property of glioblastoma cells. ${ }^{7}$ Let-7 miRNA has been implicated in inflammation associated cellular transformation ${ }^{90}$ and targeting $\mathrm{K}^{-\mathrm{Ras}^{6}}{ }^{6}$ (Figure 5). H19 long non-coding RNA antagonizes Let-7 miRNA ${ }^{9}$ and increases K-Ras expression by reversing Let-7-mediated miRNA interference (Figure 5). In this context, $\mathrm{H} 19$ long non-coding RNA regulates cellular transformation and potentiates breast and lung tumorigenesis. ${ }^{91}$ An LCS6 variant allele associated with $\mathrm{K}$-Ras overexpression owing to a mutation in the miRNA-binding site increased the risk of lung cancer among smokers. ${ }^{8}$ Of note, smoking induces spontaneous mutations within the KRAS gene. ${ }^{92}$ In a spontaneous lung cancer mouse model driven by $K$-Ras ${ }^{G 12 D}$ and $p 53^{-/-}$genotype, miRNA-214 was found to be overexpressed. Impeding miR-214 blocked tumor growth to demonstrate the tumor-promoting role of miR-214 in a K-Ras mutant system ${ }^{93}$ (Figure 5). In breast cancer, miR-1 (hsa-miR-1) targets K-Ras to impede tumor growth and metastasis, thereby acting as a tumor suppressor. ${ }^{13}$ In addition, miRNA-622 targets K-Ras to inhibit transformation in vitro and tumorigenesis in vivo ${ }^{12}$ (Figure 5). Similarly, miR-217 targets K-Ras to inhibit cellular transformation and tumor growth in pancreatic ductal adenocarcinoma of mice ${ }^{14}$ (Figure 5). In glioblastoma multiforme, K-Ras expression was found to be necessary to maintain tumors in vivo, and loss of K-Ras led to apoptotic clearance of these cells. ${ }^{94}$ K-Ras was found to influence the expression of the long non-coding RNA ANRIL, ${ }^{95}$ which promotes lung cancer by inhibiting apoptosis ${ }^{96}$ (Figure 5).

K-Ras also exerts its oncogenic effects through ERK-1/2 ${ }^{97}$ and is negatively regulated by the small nucleolar RNA SNORD50A, and SNORD50B-mediated direct targeting of K-Ras and CRISPR/Cas9mediated deletion of these small nucleolar RNAs enhance tumorigenesis. ${ }^{98}$

Taken together, these studies reiterate and confirm the fact that cellular transformation and genomic instability are two prominent features that are essential for K-Ras-driven tumorigenesis and highlight the dominance of genetic factors in K-Ras-driven tumorigenesis.

\section{SUMMARY AND FUTURE PERSPECTIVES}

K-Ras induces apoptosis through oxidative stress and then detoxifies ROS to induce DNA damage repair to regulate cellular transformation through the blebbishield emergency program and induces genomic instability to drive tumorigenesis. K-Ras could possibly mediate therapy resistance and relapse through the blebbishield emergency program because chemoresistant cancer clones were found to have a link to $\mathrm{K}$-Ras. ${ }^{5} \mathrm{~K}$-Ras in general is known to suppress the apoptotic program of death receptors and to redirect cells toward metastasis, ${ }^{99}$ which explains the importance of the blebbishield emergency program. ${ }^{44}$ In this context, inhibition of CDK4/6 gains importance as it could increase sensitivity to paclitaxel in K-Ras mutant cells ${ }^{100}$ or induce senescence and impede tumor growth with autophagy inhibitors. $^{101}$

A new avenue of miRNA therapeutics targeting K-Ras (based on tumor suppressor miRNAs Let-7a, miR-143, miR-145 and miR-200 family) is emerging at the preclinical level, highlighting the importance of K-Ras miRNA regulatory networks in cancer therapy. ${ }^{102}$ Although the expression of miR-26a in lung cancer suggests a link to K-Ras activation, the nature of this regulation remains unexplored (Figure 5). The introduction of miRNA-zippers, which lock two miRNAs together to inactivate both miRNAs ${ }^{103}$ and iExosomes ${ }^{104}$ (exosomes with siRNA or shRNA targeting KRAS ${ }^{\mathrm{G} 12 \mathrm{D}}$ mRNA), provides more choices for miRNA-based therapeutics. Thus, evaluating K-Ras in cancer relapse and expanding miRNA/ RNAi therapeutics against K-Ras-driven cancers are attractive and emerging avenues of research. Despite smoking being linked to mutational activation of K-Ras and driving tumorigenesis in the context of p53 mutations, ${ }^{105}$ an evaluation of oncogenic viruses in the induction of K-Ras mutations is much needed. This review will also serve as a model to explore the mechanism of other 
oncogenes in various cancers for better understanding and better therapeutic development in the future.

\section{CONFLICT OF INTEREST}

The authors declare no conflict of interest.

\section{ACKNOWLEDGEMENTS}

The authors sincerely thank the University of Texas MD Anderson Cancer Center for literature access.

\section{REFERENCES}

1 Dean M, Fojo T, Bates S. Tumour stem cells and drug resistance. Nat Rev Cancer 2005; 5: 275-284.

2 Tran E, Robbins PF, Lu YC, Prickett TD, Gartner JJ, Jia L et al. T-cell transfer therapy targeting mutant KRAS in cancer. N Engl J Med 2016; 375: 2255-2262.

3 Bartos JD, Stoler DL, Matsui S, Swede H, Willmott LJ, Sait SN et al. Genomic heterogeneity and instability in colorectal cancer: spectral karyotyping, glutathione transferase-Ml and ras. Mutat Res 2004; 568: 283-292.

4 Pylayeva-Gupta Y, Grabocka E, Bar-Sagi D. RAS oncogenes: weaving a tumorigenic web. Nat Rev Cancer 2011; 11: 761-774.

5 Hjortland GO, Meza-Zepeda LA, Beiske K, Ree AH, Tveito S, Hoifodt $\mathrm{H}$ et al. Genome wide single cell analysis of chemotherapy resistant metastatic cells in a case of gastroesophageal adenocarcinoma. BMC Cancer 2011; 11: 455.

6 Johnson SM, Grosshans H, Shingara J, Byrom M, Jarvis R, Cheng A et al. RAS is regulated by the let-7 microRNA family. Cell 2005; 120: 635-647.

7 Wang XR, Luo H, Li HL, Cao L, Wang XF, Yan W et al. Overexpressed let-7a inhibits glioma cell malignancy by directly targeting K-ras, independently of PTEN. Neuro-oncology 2013; 15: 1491-1501.

8 Chin LJ, Ratner E, Leng S, Zhai R, Nallur S, Babar I et al. A SNP in a let-7 microRNA complementary site in the KRAS $3^{\prime}$ untranslated region increases non-small cell lung cancer risk. Cancer Res 2008; 68: 8535-8540.

9 Ma C, Nong K, Zhu H, Wang W, Huang X, Yuan Z et al. H19 promotes pancreatic cancer metastasis by derepressing let-7's suppression on its target HMGA2mediated EMT. Tumour Biol 2014; 35: 9163-9169.

10 You C, Liang H, Sun W, Li J, Liu Y, Fan Q et al. Deregulation of the miR-16-KRAS axis promotes colorectal cancer. Sci Rep 2016; 6: 37459.

11 Tsang WP, Kwok $\Pi$. The miR-18a* microRNA functions as a potential tumor suppressor by targeting on K-Ras. Carcinogenesis 2009; 30: 953-959.

12 Han Z, Yang Q, Liu B, Wu J, Li Y, Yang C et al. MicroRNA-622 functions as a tumor suppressor by targeting K-Ras and enhancing the anticarcinogenic effect of resveratrol. Carcinogenesis 2012; 33: 131-139.

13 Liu R, Li J, Lai Y, Liao Y, Qiu W. Hsa-miR-1 suppresses breast cancer development by down-regulating K-ras and long non-coding RNA MALAT1. Int J Biol Macromol 2015; 81: 491-497.

14 Zhao WG, Yu SN, Lu ZH, Ma YH, Gu YM, Chen J. The miR-217 microRNA functions as a potential tumor suppressor in pancreatic ductal adenocarcinoma by targeting KRAS. Carcinogenesis 2010; 31: 1726-1733.

15 Chan IT, Kutok JL, Williams IR, Cohen S, Kelly L, Shigematsu H et al. Conditional expression of oncogenic K-ras from its endogenous promoter induces a myeloproliferative disease. J Clin Invest 2004; 113: 528-538.

16 Moody CA, Laimins LA. Human papillomavirus oncoproteins: pathways to transformation. Nat Rev Cancer 2010; 10: 550-560.

17 Tran MN, Goodwin Jinesh G, McConkey DJ, Kamat AM. Bladder cancer stem cells. Curr Stem Cell Res Ther 2010; 5: 387-395.

18 Fiala O, Buchler T, Mohelnikova-Duchonova B, Melichar B, Matejka VM, Holubec L et al. G12V and G12A KRAS mutations are associated with poor outcome in patients with metastatic colorectal cancer treated with bevacizumab. Tumour Biol 2016; 37: 6823-6830.

19 Nadal E, Beer DG, Ramnath N. KRAS-G12C mutation is associated with poor outcome in surgically resected lung adenocarcinoma. J Thorac Oncol 2015; 10: e9-10.

20 Monticone M, Biollo E, Maffei M, Donadini A, Romeo F, Storlazzi CT et al. Gene expression deregulation by KRAS G12D and G12V in a BRAF V600E context. Mol Cancer 2008; 7: 92.

21 Niemela JE, Lu L, Fleisher TA, Davis J, Caminha I, Natter M et al. Somatic KRAS mutations associated with a human nonmalignant syndrome of autoimmunity and abnormal leukocyte homeostasis. Blood 2011; 117: 2883-2886.

22 Kumar SS, Price TJ, Mohyieldin O, Borg M, Townsend A, Hardingham JE. KRAS G13D mutation and sensitivity to cetuximab or panitumumab in a colorectal cancer cell line model. Gastrointest Cancer Res 2014; 7: 23-26.
23 Prior IA, Lewis PD, Mattos C. A comprehensive survey of Ras mutations in cancer. Cancer Res 2012; 72: 2457-2467.

24 Andreyev HJ, Norman AR, Cunningham D, Oates JR, Clarke PA. Kirsten ras mutations in patients with colorectal cancer: the multicenter "RASCAL" study. $J$ Natl Cancer Inst 1998; 90: 675-684.

25 Keohavong P, DeMichele MA, Melacrinos AC, Landreneau RJ, Weyant RJ, Siegfried JM. Detection of K-ras mutations in lung carcinomas: relationship to prognosis. Clin Cancer Res 1996; 2: 411-418.

26 Hobbs GA, Wittinghofer A, Der CJ. Selective targeting of the KRAS G12C mutant: kicking KRAS when it's down. Cancer Cell 2016; 29: 251-253.

27 Serra RW, Fang M, Park SM, Hutchinson L, Green MR. A KRAS-directed transcriptional silencing pathway that mediates the CpG island methylator phenotype. Elife 2014; 3: e02313.

28 Tsai FD, Lopes MS, Zhou M, Court H, Ponce O, Fiordalisi JJ et al. K-Ras4A splice variant is widely expressed in cancer and uses a hybrid membranetargeting motif. Proc Natl Acad Sci USA 2015; 112: 779-784.

29 Ostrem JM, Shokat KM. Direct small-molecule inhibitors of KRAS: from structural insights to mechanism-based design. Nat Rev Drug Discov 2016; 15: 771-785.

30 Ardito CM, Gruner BM, Takeuchi KK, Lubeseder-Martellato C, Teichmann N, Mazur PK et al. EGF receptor is required for KRAS-induced pancreatic tumorigenesis. Cancer Cell 2012; 22: 304-317.

31 Schimanski CC, Zimmermann T, Schmidtmann I, Gockel I, Lang H, Galle PR et al. K-ras mutation status correlates with the expression of VEGFR1, VEGFR2, and PDGFRalpha in colorectal cancer. Int J Colorectal Dis 2010; 25: 181-186.

32 Tape CJ, Ling S, Dimitriadi M, McMahon KM, Worboys JD, Leong HS et al. Oncogenic KRAS regulates tumor cell signaling via stromal reciprocation. Cell 2016; 165: 910-920.

33 Kim WY, Prudkin L, Feng L, Kim ES, Hennessy B, Lee JS et al. Epidermal growth factor receptor and K-Ras mutations and resistance of lung cancer to insulin-like growth factor 1 receptor tyrosine kinase inhibitors. Cancer 2012; 118: 3993-4003.

34 Balaji K, Vijayaraghavan S, Diao L, Tong P, Fan Y, Carey JP et al. AXL inhibition suppresses the DNA damage response and sensitizes cells to PARP inhibition in multiple cancers. Mol Cancer Res 2017; 15: 45-58.

35 Park MT, Kim MJ, Suh Y, Kim RK, Kim H, Lim EJ et al. Novel signaling axis for ROS generation during K-Ras-induced cellular transformation. Cell Death Differ 2014; 21: $1185-1197$.

36 Jinesh GG, Taoka R, Zhang Q, Gorantla S, Kamat AM. Novel PKC-zeta to p47 phox interaction is necessary for transformation from blebbishields. Sci Rep 2016; 6: 23965.

37 Alvarez-Moya B, Lopez-Alcala C, Drosten M, Bachs O, Agell N. K-Ras4B phosphorylation at Ser181 is inhibited by calmodulin and modulates K-Ras activity and function. Oncogene 2010; 29: 5911-5922.

38 Barcelo C, Paco N, Morell M, Alvarez-Moya B, Bota-Rabassedas N, Jaumot M et al. Phosphorylation at Ser-181 of oncogenic KRAS is required for tumor growth. Cancer Res 2014; 74: 1190-1199.

39 Cox AD, Der CJ. The dark side of Ras: regulation of apoptosis. Oncogene 2003; 22: 8999-9006.

40 Jinesh GG, Laing NM, Kamat AM. Smac mimetic with TNF-alpha targets Pim-1 isoforms and reactive oxygen species production to abrogate transformation from blebbishields. Biochem J 2016; 473: 99-107.

41 Jinesh GG, Kamat AM. RalBP1 and p19-VHL play an oncogenic role, and p30-VHL plays a tumor suppressor role during the blebbishield emergency program. Cell Death Discov 2017; 3: 17023.

42 Jinesh GG, Choi W, Shah JB, Lee EK, Willis DL, Kamat AM. Blebbishields, the emergency program for cancer stem cells: sphere formation and tumorigenesis after apoptosis. Cell Death Differ 2013; 20: 382-395.

43 Jinesh GG, Kamat AM. Endocytosis and serpentine filopodia drive blebbishieldmediated resurrection of apoptotic cancer stem cells. Cell Death Discov 2016; 2: 15069.

44 Jinesh GG, Molina JR, Huang L, Laing NM, Mills GB, Bar-Eli M et al. Mitochondrial oligomers boost glycolysis in cancer stem cells to facilitate blebbishieldmediated transformation after apoptosis. Cell Death Discov2016; 2: 16003.

$45 \mathrm{Wu}$ CC, Bratton SB. Regulation of the intrinsic apoptosis pathway by reactive oxygen species. Antioxid Redox Signal 2013; 19: 546-558.

46 Shi Y, Nikulenkov F, Zawacka-Pankau J, Li H, Gabdoulline R, Xu J et al. ROSdependent activation of JNK converts p53 into an efficient inhibitor of oncogenes leading to robust apoptosis. Cell Death Differ 2014; 21: 612-623.

47 Tao S, Wang S, Moghaddam SJ, Ooi A, Chapman E, Wong PK et al. Oncogenic KRAS confers chemoresistance by upregulating NRF2. Cancer Res 2014; 74: 7430-7441.

48 Yilmaz A, Mohamed N, Patterson KA, Tang Y, Shilo K, Villalona-Calero MA et al. Increased NQO1 but not c-MET and survivin expression in non-small cell lung carcinoma with KRAS mutations. Int J Environ Res Public Health 2014; 11: 9491-9502. 
49 DeNicola GM, Karreth FA, Humpton TJ, Gopinathan A, Wei C, Frese K et al. Oncogene-induced Nrf2 transcription promotes ROS detoxification and tumorigenesis. Nature 2011; 475: 106-109.

50 Purdom-Dickinson SE, Sheveleva EV, Sun H, Chen QM. Translational control of nrf2 protein in activation of antioxidant response by oxidants. Mol Pharmacol 2007; 72: 1074-1081.

51 Romanelli A, Martin KA, Toker A, Blenis J. p70 S6 kinase is regulated by protein kinase Czeta and participates in a phosphoinositide 3-kinase-regulated signalling complex. Mol Cell Biol 1999; 19: 2921-2928.

52 Konishi H, Karakas B, Abukhdeir AM, Lauring J, Gustin JP, Garay JP et al. Knock-in of mutant K-ras in nontumorigenic human epithelial cells as a new model for studying K-ras mediated transformation. Cancer Res 2007; 67: 8460-8467.

53 Jinesh GG, Kamat AM. Blebbishield emergency program: an apoptotic route to cellular transformation. Cell Death Differ 2016; 23: 757-758.

54 Jinesh GG, Kamat AM. Blebbishields and mitotic cells exhibit robust macropinocytosis. Biofactors 2016; 43: 181-186.

55 Goodwin Jinesh G, Willis DL, Kamat AM. Bladder cancer stem cells: biological and therapeutic perspectives. Curr Stem Cell Res Ther 2014; 9: 89-101.

56 Jinesh GG, Mokkapati S, Zhu K, Morales EE. Pim kinase isoforms: devils defending cancer cells from therapeutic and immune attacks. Apoptosis 2016; 21: 1203-1213.

57 Jayakumar S, Pal D, Sandur SK. Nrf2 facilitates repair of radiation induced DNA damage through homologous recombination repair pathway in a ROS independent manner in cancer cells. Mutat Res 2015; 779: 33-45.

58 Jinesh GG, Chunduru S, Kamat AM. Smac mimetic enables the anticancer action of BCG-stimulated neutrophils through TNF-alpha but not through TRAIL and FasL. J Leukoc Biol 2012; 92: 233-244.

59 Jinesh GG, Kamat AM. Redirecting neutrophils against bladder cancer cells by BCG and Smac mimetic combination. Oncoimmunology 2012; 1: 1161-1162.

60 Danial NN. BAD: undertaker by night, candyman by day. Oncogene 2008; 27 S53-S70.

61 Jinesh GG, Kamat AM. The blebbishield emergency program overrides chromosomal instability and phagocytosis checkpoints in cancer stem cells. Cancer Res 2017; doi: 10.1158/0008-5472.CAN-17-0522

62 Jinesh GG, Ganiraju M, Chinedu M, Keith AB, Kamat AM. Surface PD-L1, E-cadherin, CD24, and VEGFR2 as markers of epithelial cancer stem cells associated with rapid tumorigenesis. Sci Rep 2017; 7: 9602.

63 Milo GE, Kurian P, Kirsten E, Kun E. Inhibition of carcinogen-induced cellular transformation of human fibroblasts by drugs that interact with the poly(ADPribose) polymerase system. Initial evidence for the development of transformation resistance. FEBS Lett 1985; 179: 332-336.

64 Taoka RR, Jinesh GG, Xue W, Safe S, Kamat AM. CF3DODA-Me induces apoptosis, degrades Sp1 and blocks the transformation phase of the blebbishield emergency program. Apoptosis 2017; 22: 719-729.

65 Johnson L, Mercer K, Greenbaum D, Bronson RT, Crowley D, Tuveson DA et al. Somatic activation of the K-ras oncogene causes early onset lung cancer in mice. Nature 2001; 410: 1111-1116.

66 Ortega J, Li JY, Lee S, Tong D, Gu L, Li GM. Phosphorylation of PCNA by EGFR inhibits mismatch repair and promotes misincorporation during DNA synthesis. Proc Natl Acad Sci USA 2015; 112: 5667-5672.

67 Brentnall TA, Chen R, Lee JG, Kimmey MB, Bronner MP, Haggitt RC et al. Microsatellite instability and K-ras mutations associated with pancreatic adenocarcinoma and pancreatitis. Cancer Res 1995; 55: 4264-4267.

68 Lagarda H, Catasus L, Arguelles R, Matias-Guiu X, Prat J. K-ras mutations in endometrial carcinomas with microsatellite instability. J Pathol 2001; 193: 193-199.

69 Lo AW, Sabatier L, Fouladi B, Pottier G, Ricoul M, Murnane JP. DNA amplification by breakage/fusion/bridge cycles initiated by spontaneous telomere loss in a human cancer cell line. Neoplasia 2002; 4: 531-538.

70 Feijoo P, Dominguez D, Tusell L, Genesca A. Telomere-dependent genomic integrity: evolution of the fusion-bridge-breakage cycle concept. Curr Pharm Des 2014; 20: 6375-6385.

71 Hahnel PS, Enders B, Sasca D, Roos WP, Kaina B, Bullinger L et al. Targeting components of the alternative NHEJ pathway sensitizes KRAS mutant leukemic cells to chemotherapy. Blood 2014; 123: 2355-2366.

72 Weiss MB, Vitolo MI, Mohseni M, Rosen DM, Denmeade SR, Park BH et al. Deletion of p53 in human mammary epithelial cells causes chromosomal instability and altered therapeutic response. Oncogene 2010; 29: 4715-4724.

73 Rodrigues CF, Urbano AM, Matoso E, Carreira I, Almeida A, Santos P et al. Human bronchial epithelial cells malignantly transformed by hexavalent chromium exhibit an aneuploid phenotype but no microsatellite instability. Mutat Res 2009; 670: 42-52.

74 Tang FH, Hsieh TH, Hsu CY, Lin HY, Long CY, Cheng KH et al. KRAS mutation coupled with p53 loss is sufficient to induce ovarian carcinosarcomas in mice. Int J Cancer 2017; 140: 1860-1869.
75 Xu S, Wang T, Yang Z, Li Y, Li W, Wang S et al. miR-26a desensitizes non-small cell lung cancer cells to tyrosine kinase inhibitors by targeting PTPN13. Oncotarget 2016; 7: 45687-45701.

76 Castellano L, Dabrowska A, Pellegrino L, Ottaviani S, Cathcart P, Frampton AE et al. Sustained expression of miR-26a promotes chromosomal instability and tumorigenesis through regulation of CHFR. Nucleic Acids Res 2017; 45: 4401-4412.

77 Fehrmann RS, Karjalainen JM, Krajewska M, Westra HJ, Maloney D, Simeonov A et al. Gene expression analysis identifies global gene dosage sensitivity in cancer. Nat Genet 2015; 47: 115-125.

78 Baykara O, Bakir B, Buyru N, Kaynak K, Dalay N. Amplification of chromosome 8 genes in lung cancer. J Cancer 2015; 6: 270-275.

79 Ying H, Kimmelman AC, Lyssiotis CA, Hua S, Chu GC, Fletcher-Sananikone E et al. Oncogenic Kras maintains pancreatic tumors through regulation of anabolic glucose metabolism. Cell 2012; 149: 656-670.

80 Kerr EM, Gaude E, Turrell FK, Frezza C, Martins CP. Mutant Kras copy number defines metabolic reprogramming and therapeutic susceptibilities. Nature 2016; 531: 110-113.

81 Shim H, Dolde C, Lewis BC, Wu CS, Dang G, Jungmann RA et al. c-Myc transactivation of LDH-A: implications for tumor metabolism and growth. Proc Natl Acad Sci USA 1997; 94: 6658-6663.

82 Fantin VR, St-Pierre J, Leder P. Attenuation of LDH-A expression uncovers a link between glycolysis, mitochondrial physiology, and tumor maintenance. Cancer Cell 2006; 9: 425-434.

83 Beyer K, Altendorf-Hofmann A, Chen Y, Bickel K, Petersen I. KRAS and aneusomy of chromosomes 4, 10 and 12 in colorectal carcinomas. Pathol Res Pract 2015; 211: 646-651.

84 Kumar MS, Lu J, Mercer KL, Golub TR, Jacks T. Impaired microRNA processing enhances cellular transformation and tumorigenesis. Nat Genet 2007; 39: 673-677

85 Suzuki HI, Yamagata K, Sugimoto K, Iwamoto T, Kato S, Miyazono K. Modulation of microRNA processing by p53. Nature 2009; 460: 529-533.

86 Hara T, Jones MF, Subramanian M, Li XL, Ou O, Zhu Y et al. Selective targeting of KRAS-mutant cells by miR-126 through repression of multiple genes essential for the survival of KRAS-mutant cells. Oncotarget 2014; 5: 7635-7650.

87 Zhou Y, Dang J, Chang KY, Yau E, Aza-Blanc P, Moscat J et al. miR-1298 inhibits mutant KRAS-driven tumor grrowth by repressing FAK and LAMB3. Cancer Res 2016; 76: 5777-5787.

88 Hatley ME, Patrick DM, Garcia MR, Richardson JA, Bassel-Duby R, van Rooij E et al. Modulation of K-Ras-dependent lung tumorigenesis by MicroRNA-21. Cancer Cell 2010; 18: 282-293.

89 Kent OA, Chivukula RR, Mullendore M, Wentzel EA, Feldmann G, Lee KH et al. Repression of the miR-143/145 cluster by oncogenic Ras initiates a tumorpromoting feed-forward pathway. Genes Dev 2010; 24: 2754-2759.

90 Iliopoulos D, Hirsch HA, Struhl K. An epigenetic switch involving NF-kappaB, Lin28, Let-7 MicroRNA, and IL6 links inflammation to cell transformation. Cell 2009; 139: 693-706.

91 Barsyte-Lovejoy D, Lau SK, Boutros PC, Khosravi F, Jurisica I, Andrulis IL et al. The c-Myc oncogene directly induces the $\mathrm{H} 19$ noncoding RNA by allele-specific binding to potentiate tumorigenesis. Cancer Res 2006; 66: 5330-5337.

92 Ahrendt SA, Decker PA, Alawi EA, Zhu Yr YR, Sanchez-Cespedes M, Yang SC et al. Cigarette smoking is strongly associated with mutation of the K-ras gene in patients with primary adenocarcinoma of the lung. Cancer 2001; 92: 1525-1530.

93 Yin $Y$, Cai $X$, Chen $X$, Liang H, Zhang Y, Li J et al. Tumor-secreted miR-214 induces regulatory $T$ cells: a major link between immune evasion and tumor growth. Cell Res 2014; 24: 1164-1180.

94 Holmen SL, Williams BO. Essential role for Ras signaling in glioblastoma maintenance. Cancer Res 2005; 65: 8250-8255.

95 Kotake Y, Naemura M, Kitagawa K, Niida H, Tsunoda T, Shirasawa S et al. Oncogenic Ras influences the expression of multiple IncRNAs. Cytotechnology 2016; 68: 1591-1596

96 Nie FQ, Sun M, Yang JS, Xie M, Xu TP, Xia R et al. Long noncoding RNA ANRIL promotes non-small cell lung cancer cell proliferation and inhibits apoptosis by silencing KLF2 and P21 expression. Mol Cancer Ther 2015; 14: 268-277.

97 Weinberg F, Hamanaka R, Wheaton WW, Weinberg S, Joseph J, Lopez M et al. Mitochondrial metabolism and ROS generation are essential for Kras-mediated tumorigenicity. Proc Natl Acad Sci 2010; 107: 8788-8793.

98 Siprashvili Z, Webster DE, Johnston D, Shenoy RM, Ungewickell AJ, Bhaduri A et al. The noncoding RNAs SNORD50A and SNORD50B bind K-Ras and are recurrently deleted in human cancer. Nat Genet 2016; 48: 53-58.

99 Hoogwater FJ, Nijkamp MW, Smakman N, Steller EJ, Emmink BL, Westendorp BF et al. Oncogenic K-Ras turns death receptors into metastasis-promoting receptors in human and mouse colorectal cancer cells. Gastroenterology 2010; 138: 2357-2367. 
100 Zhang XH, Cheng Y, Shin JY, Kim JO, Oh JE, Kang JH. A CDK4/6 inhibitor enhances cytotoxicity of paclitaxel in lung adenocarcinoma cells harboring mutant KRAS as well as wild-type KRAS. Cancer Biol Ther 2013; 14: 597-605.

101 Vijayaraghavan S, Karakas C, Doostan I, Chen X, Bui T, Yi M et al. CDK4/6 and autophagy inhibitors synergistically induce senescence in $\mathrm{Rb}$ positive cytoplasmic cyclin E negative cancers. Nat Commun 2017; 8: 15916.

102 Rupaimoole R, Slack FJ. MicroRNA therapeutics: towards a new era for the management of cancer and other diseases. Nat Rev Drug Discov 2017; 16: 203-222.

103 Meng L, Liu C, Lu J, Zhao Q, Deng S, Wang G et al. Small RNA zippers lock miRNA molecules and block miRNA function in mammalian cells. Nat Commun 2017; 8: 13964.

104 Kamerkar S, LeBleu VS, Sugimoto H, Yang S, Ruivo CF, Melo SA et al. Exosomes facilitate therapeutic targeting of oncogenic KRAS in pancreatic cancer. Nature 2017; 546: 498-503.
105 Wang Y, Zhang Z, Lubet R, You M. Tobacco smoke-induced lung tumorigenesis in mutant $\mathrm{A} / \mathrm{J}$ mice with alterations in K-ras, p53, or Ink4a/Arf. Oncogene 2005; 24: 3042-3049.

(C) $(-)$ This work is licensed under a Creative Commons AttributionCon Commercial-NoDerivs 4.0 International License. The images or other third party material in this article are included in the article's Creative Commons license, unless indicated otherwise in the credit line; if the material is not included under the Creative Commons license, users will need to obtain permission from the license holder to reproduce the material. To view a copy of this license, visit http:// creativecommons.org/licenses/by-nc-nd/4.0/

(c) The Author(s) 2018 